\title{
Analytical Model of Electrical Machines in Business Software
}

\author{
Josip NAĐ, Mario VRAŽlĆ
}

\begin{abstract}
This paper presents a possibility of using enterprise resource planning (ERP) business software for alternative analysis of electrical machines, with SAP ERP as an example of such software. Method presented is valid for all kinds of electrical machines. For the purpose of this paper, induction machine is processed. Analysis started with calculation of all six parameters of equivalent circuit, based on data determined by typical electrical measurements. Completion point is creation of steady-stay torqueslip curve. It is important to emphasize that only the standard SAP objects and functions are used for the whole procedure, without any additional programming.
\end{abstract}

Keywords: electrical machines; ERP; induction machine; steady-state characteristics

\section{INTRODUCTION}

Power given by electrical machines is base source of mechanical energy for current industry requirement, so the need for finding a way for some alternative kinds of analysis and design of electrical machines is fully justified. This paper presents the new way of induction machine (IM) analysis done by typical ERP business software.

Dynamic states of electrical machines are described by voltage and mechanical nonlinear differential equations [1]. By solving well known system for $\mathrm{AC}$ machines the steady state equivalent circuit of IM, together with formulas for calculation of the values of all six parameters of equivalent circuit can be defined. With further calculation it is easy to determine required expressions for impedance, torque, slip and current [2]. This paper will not cover the process of finding correct formulas, but the process of including all required parameters and formulas in SAP and giving the final results in the form of steady-state characteristics.

The presented procedure has three basic steps:

- calculation of IM parameters in SAP

- $\quad$ preparation of the SAP structure for simulation

- $\quad$ simulation in SAP and determining the needed values

for steady-state curves creation.

Proposed solution is based on standard SAP objects (materials, classes, work centres, activity types, cost centres, routings and production orders) and three SAP business modules: Production Planning (PP), Variant Configuration (LO-VC) and Controlling (CO). All needed functionalities covered by these modules are described in detail in $[3 \div 5]$.

\section{CALCULATION OF IM PARAMETERS IN SAP}

This procedure step has three technical steps in SAP:

- creation of characteristics, classes and dependencies (for measured and calculated data)

- creation of material and configuration profile

- value calculation for all six IM equivalent circuit parameters (Fig. 1).
Symbols V1 and V2 stay for stator and rotor phase voltages, respectively. All parameters are defined in Tab. 3.

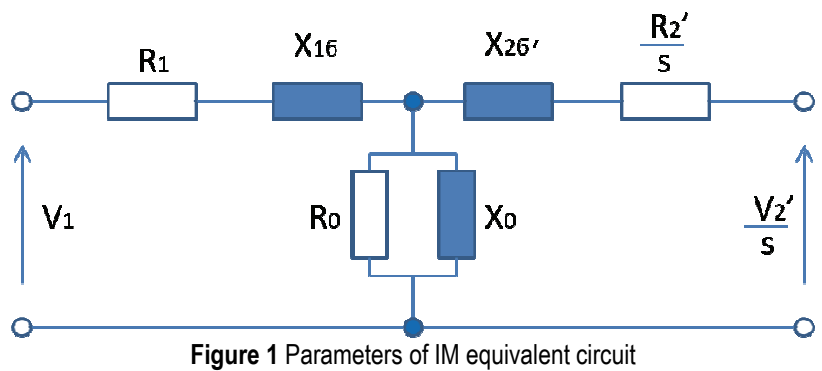

Nominal data of three phase slip-ring IM used in this example are: $1250 \mathrm{~kW}, 6000 \mathrm{~V}, 138 \mathrm{~A}$ and $1485 \mathrm{r} / \mathrm{min}$ [6]. Some measured data were also available and for all of them SAP characteristics are created (Tab. 1). In order to calculate all parameters of equivalent circuit, the standard form of LO-VC functionality is used.

Table 1 Measured data and SAP Characteristics

\begin{tabular}{|l|c|c|}
\hline \multicolumn{1}{|c|}{ Parameter } & Value & SAP Characteristic \\
\hline Stator Resistance & $0,180 \Omega$ & Z_FER_M01 \\
\hline No-Load Impedance & $118,229 \Omega$ & Z_FER_M02 \\
\hline No-Load Current & $29,3 \mathrm{~A}$ & Z_FER_M03 \\
\hline No-Load Power & $28900 \mathrm{~W}$ & Z_FER_M04 \\
\hline No-Load Power factor & 0,0951 & Z_FER_M05 \\
\hline Short-Circuit Impedance & $6,828 \Omega$ & Z_FER_M06 \\
\hline Short-Circuit Current & $138,0 \mathrm{~A}$ & Z_FER_M07 \\
\hline Short-Circuit Power & $44880 \mathrm{~W}$ & Z_FER_M08 \\
\hline Short-Circuit Power factor & 0,1151 & Z_FER_M09 \\
\hline
\end{tabular}

Based on measured data, three additional parameters should be calculated: Equivalent no-load power, Short circuit resistance and Short circuit reactance. For each of them, both characteristics and dependencies are created (Tab. 2). Technical equations for them are well known [1]. What will be shown is presentation of such equations in SAP, using characteristics and dependencies.

Table 2 IM calculated data

\begin{tabular}{|l|c|c|}
\hline \multicolumn{1}{|c|}{ Parameter } & SAP Characteristic & SAP Dependency \\
\hline Equiv. No-Load Power & Z_FER_C03 & Z_FER_C03 \\
\hline Short-Circuit Resistance & Z_FER_C04 & Z_FER_C04 \\
\hline Short-Circuit Reactance & Z_FER_C05 & Z_FER_C05 \\
\hline
\end{tabular}

Dependency for characteristic Equivalent no-load power (Z_FER_CO3) is shown in Figs. 2a and $2 b$. 


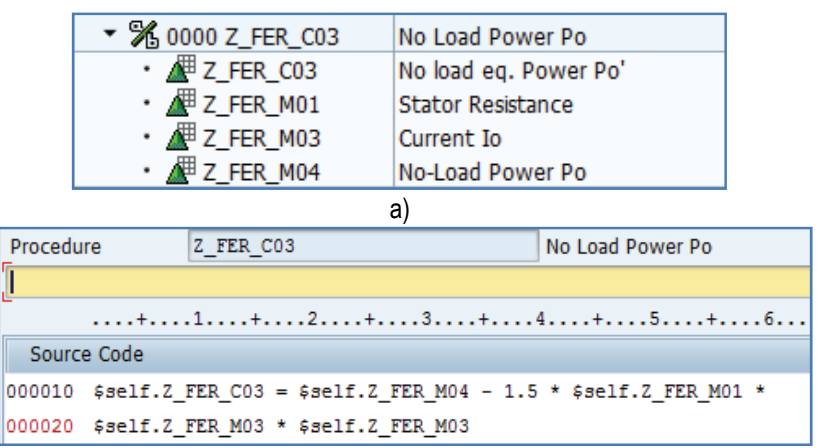

b)

Figure 2 a) Characteristics used in dependency Z_FER_CO3, b) Formula in dependency Z_FER_CO3

Dependency for characteristic short circuit resistance (Z_FER_CO4) is shown in Figs. 3a and 3b.

\begin{tabular}{|c|c|}
\hline " 0000 Z_FER_C04 & Short-Circuit Resistance Rks \\
\hline - $\Delta$ 电 Z_FER_C04 & Resistance short-circuit Rks \\
\hline - $\triangle$ 田Z_FER_M07 & Current Ik \\
\hline - $\Delta$ 䧉 Z_FER_M08 & Power Pk \\
\hline
\end{tabular}

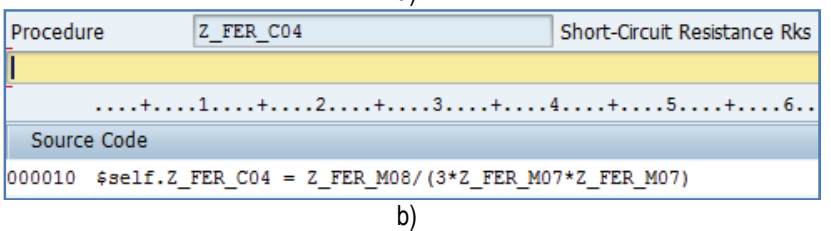

Figure 3 a) Characteristics used in dependency Z_FER_CO4, b) Formula in dependency Z_FER_CO4

Dependency for characteristic short circuit reactance (Z_FER_CO5) is shown in Figs. $4 \mathrm{a}$ and $4 \mathrm{~b}$.

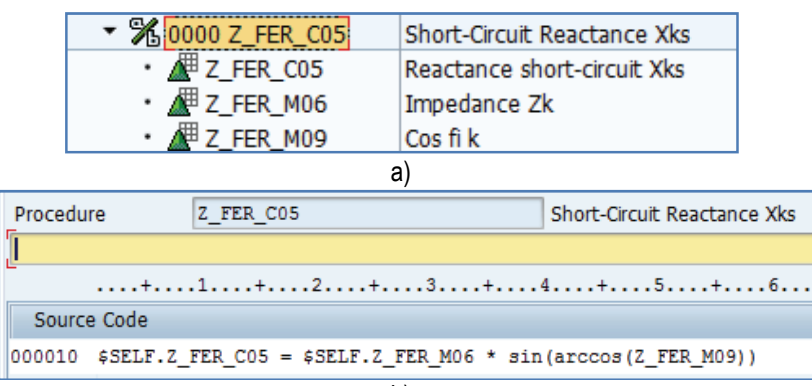

Figure 4 a) Characteristics used in dependency Z_FER_CO5, b) Formula in dependency Z_FER_CO5

Next task is calculation of all six equivalent circuit parameters (Tab. 3). They should also be created in SAP as characteristics and their values are given by formulas in dependencies.

Table 3 IM equivalent circuit parameters
\begin{tabular}{|l|c|c|}
\hline \multicolumn{1}{|c|}{ Parameter } & $\begin{array}{c}\text { SAP } \\
\text { Characteristic }\end{array}$ & $\begin{array}{c}\text { SAP } \\
\text { Dependency }\end{array}$ \\
\hline $\mathrm{R}_{1}$ (Stator phase resistance) & Z_FER_R01 & Z_FER_R01 \\
\hline $\mathrm{R}_{2}{ }^{\prime}$ (Eq. rotor phase resistance) & Z_FER_R02 & Z_FER_R02 \\
\hline $\mathrm{R}_{0}$ (Core losses resistance) & Z_FER_R03 & Z_FER_R03 \\
\hline $\mathrm{X}_{0}$ (Magnetizing reactance) & Z_FER_R04 & Z_FER_R04 \\
\hline $\mathrm{X}_{1 \sigma}$ (Stator leakage reactance) & Z_FER_R05 & Z_FER_R05 \\
\hline $\mathrm{X}_{2 \sigma}{ }^{\prime}$ (Rotor leakage reactance) & Z_FER_R06 & Z_FER_R06 \\
\hline
\end{tabular}

All six dependencies from Tab. 3 are created in the same way as dependencies from Tab. 2. An example for Stator phase resistance (Z_FER_R01) is given in Fig. 5.

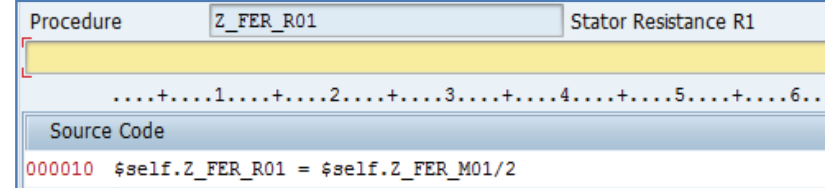

Figure 5 Dependency for stator phase resistance

After all parameters are connected and dependencies are created, the configuration object (SAP configurable material) should be defined (Fig. 6). After all dependencies are connected to material via configuration profile, configuration simulation can start.

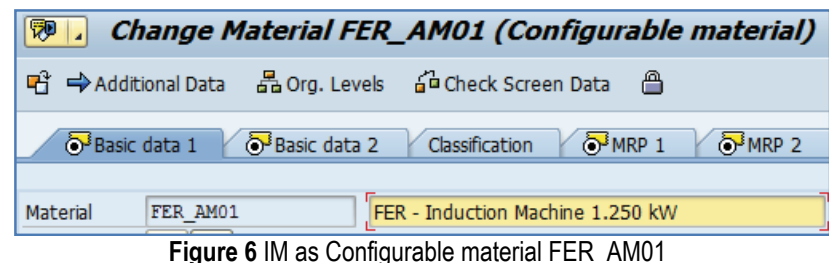

First step in configuration simulation is to enter measured values from Tab. 1. An easy way to use screen appears with possibility to enter all known values (Fig. 7).

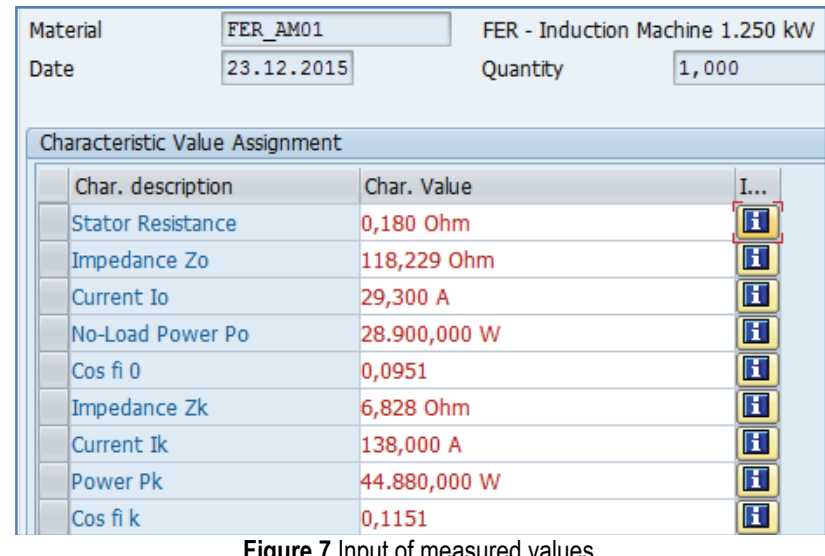

When all fields are filled, the final values for equivalent circuit parameters appear as calculated (Fig. 8). With values for these parameters, the system for simulation and creation of the steady-state characteristics is prepared. This process can be continued in the same way as calculating values for equivalent circuit parameters (using $\mathrm{LO}-\mathrm{VC}$ as the only functionality needed), but in order to show different possibilities, some other options are tried out.

\begin{tabular}{|c|c|c|c|}
\hline \multirow{2}{*}{$\begin{array}{l}\text { Material } \\
\text { Date }\end{array}$} & FER_AM01 & \multicolumn{2}{|c|}{ FER - Induction Machine $1.250 \mathrm{~kW}$} \\
\hline & 24.12 .2015 & \multicolumn{2}{|c|}{ Quantity $\quad[1,000$} \\
\hline \multicolumn{4}{|c|}{ Characteristic Value Assignment } \\
\hline \multicolumn{2}{|c|}{ Char. description } & Char. Value & I... \\
\hline \multicolumn{2}{|c|}{ Stator Phase Resistance R1 } & $0,090 \mathrm{Ohm}$ & 国 \\
\hline \multicolumn{2}{|c|}{ Eq. Rotor Phase Resistance R2' } & $0,696 \mathrm{Ohm}$ & 田 \\
\hline \multicolumn{2}{|c|}{ Resistance Ro } & $9,756 \mathrm{Ohm}$ & 田 \\
\hline \multicolumn{2}{|c|}{ Reactance Xo } & $117,693 \mathrm{Ohm}$ & i \\
\hline \multicolumn{2}{|c|}{ Leakage Reactance X1s } & $3,391 \mathrm{Ohm}$ & I \\
\hline \multicolumn{2}{|c|}{ Leakage Reactance X2s' } & 3,391 Ohm & 国 \\
\hline
\end{tabular}

Figure 8 Calculated equivalent circuit parameters

So, in the next section one different way of formula processing in SAP is described. Value of parameters 
needed for IM steady-state characteristic will be calculated by using two other SAP modules, PP and CO.

\section{PREPARATION FOR SIMULATION}

When using PP and $\mathrm{CO}$ modules, preparation for simulation consists of three technical steps in SAP:

- creation of constants and formulas required for defining all parameters of IM equivalent circuit

- creation of activity types, cost centres and work centres in order to collect all constants and formulas

- creation of materials and routings.

\subsection{Parameters as Formula Constants}

Six parameters of IM equivalent circuit are listed below, with names given in SAP and technical names from Tab. 3:

- $\quad \mathrm{K} 1=\mathrm{R}_{1}$ (stator phase resistance)

- $\quad K 2=R_{2}{ }^{\prime}$ (equivalent rotor phase resistance)

- $\mathrm{K} 3=\mathrm{R}_{0}$ (core loss resistance)

- $\quad \mathrm{K} 4=\mathrm{X}_{1 \sigma}$ (stator leakage reactance)

- $\quad \mathrm{K} 5=\mathrm{X}_{2 \sigma}{ }^{\prime}$ (rotor leakage reactance)

- $\mathrm{K} 6=\mathrm{X}_{0}$ (magnetizing reactance).

All six parameters will be included in our procedure with the help of Formula constants, which are the basic part of Work centre master data. After all six parameters are defined, they can be used in formulas for electromagnetic torque and rotor / stator current.

What follows is the way for defining parameters and formulas in SAP. Fig. 9 shows the way for defining stator resistance $R_{1}$. Parameter $\mathrm{K} 1$ is defined with the origin "Work centre constant":

\begin{tabular}{|l|l|}
\hline Parameter & K1 \\
\hline Origin & 1 Work center constant \\
\hline Attributes & \\
\hline Parameter text & Resist. R1 \\
\hline Keyword & Resistance R1 \\
\hline Dimension & RESIST \\
\hline Standard Value & 1 \\
\hline Standard value unit & OHM \\
\hline
\end{tabular}

Figure 9 Stator resistance definition

Fig. 10 shows example of grouping all six parameters of IM equivalent circuit.

\begin{tabular}{|c|c|c|c|}
\hline \multicolumn{4}{|c|}{ [ T36(1)/800 Formula Constants } \\
\hline Param. & Parameter text & Value & Un. \\
\hline K1 & Stator ph.resist. R1 & 0,090 & $\mathrm{OHM}$ \\
\hline K2 & Rotor ph.resist. R2' & 0,695 & $\mathrm{OHM}$ \\
\hline K3 & Field resistance Ro & 11,176 & $\mathrm{OHM}$ \\
\hline K4 & Leakage React. X1 & 3,391 & $\mathrm{OHM}$ \\
\hline K5 & Leakage React. X2' & 3,391 & $\mathrm{OHM}$ \\
\hline K6 & Field Reactance Xo & 117,693 & OHM \\
\hline
\end{tabular}

Figure $10 \mathrm{IM}$ equivalent circuit parameters

After all six parameters are included in SAP, two additional parameters should be created:

- $\quad$ nominal voltage (KP1)

- $\quad$ synchronous speed (KP2).
For both of them User parameters in routings are used. Fig. 11 shows the way for defining synchronous speed as parameter with the origin "User defined field from operation".

\begin{tabular}{|l|l|}
\hline Parameter & KP2 \\
\hline Origin & 4 User-defined field from operation \\
\hline Attributes & \\
\hline Parameter text & Speed \\
\hline Keyword & Syncronous Speed \\
\hline Dimension & FREQU \\
\hline Standard Value & 1 \\
\hline Standard value unit & HZ \\
\hline \multicolumn{2}{|c|}{ Figure 11 Synchronous speed as SAP parameter } \\
\hline
\end{tabular}

After both user parameters are defined, they should be grouped under User fields key (FER_01, Fig. 12):

\begin{tabular}{|c|c|c|c|}
\hline \multicolumn{4}{|l|}{ User-Specific Fields } \\
\hline Field key & FER_01 & & \\
\hline Voltage & 3.460 & V & KP1 \\
\hline Sysncron. Speed & 157,080 & $\mathrm{HZ}$ & KP2 \\
\hline
\end{tabular}

Slip will be used as main parameter for simulation. This parameter will be defined with the origin "General operational value" (Fig. 13).

\begin{tabular}{|c|c|}
\hline Parameter & GP1 \\
\hline Origin & General operation value \\
\hline \multicolumn{2}{|l|}{ Attributes } \\
\hline Parameter text & Slip \\
\hline Keyword & Slip \\
\hline \multicolumn{2}{|l|}{ Dimension } \\
\hline Standard Value & 1,000 \\
\hline \multicolumn{2}{|l|}{ Standard value unit } \\
\hline Field name & MGVRG \\
\hline
\end{tabular}

Figure 13 Slip as SAP parameter

In parameter settings, existing connection with SAP field MGVRG (Operation quantity) is visible.

\subsection{Formulas for Steady-State Analysis}

Formulas from [2] will be used for static analysis. Five new parameters and five formulas for their calculation will be created in SAP.

The first parameter is $\sigma_{1}$, the dissipation factor. It is defined as follows:

$\sigma_{1}=\frac{X_{0}+X_{1 \sigma}}{X_{0}}$.

In order to have the dissipation factor in SAP, a new parameter P01 (Fig. 14) with the origin "Standard value in the operation" and simple formula key F1 (Fig. 15) were created.

For breakdown slip $S_{\max }$, described by formula (2), SAP parameter P02 and formula key F2 are created: 
$S_{\max }=\frac{\sigma_{1} \cdot R_{2}^{\prime}}{\sqrt{R_{1}^{2}+\left(X_{1 \sigma}+\sigma_{1} \cdot X_{2 \sigma}^{\prime}\right)^{2}}}$.

For breakdown torque $T_{\max }$, described by formula (3), parameter P03 and formula key F3 are created:

$$
T_{\max }=\frac{3 V_{1}^{2}}{2 \omega_{\mathrm{s}} \cdot \sigma_{1}\left[R_{1}+\sqrt{R_{1}^{2}+\left(X_{1 \sigma}+\sigma_{1} \cdot X_{2 \sigma}^{\prime}\right)^{2}}\right]} .
$$

\begin{tabular}{|l|l|}
\hline Parameter & P01 \\
\hline Origin & 2 Standard value in the operation \\
\hline Attributes & \\
\hline Parameter text & Diss. Fact. \\
\hline Keyword & Dissipation Factor \\
\hline Dimension & \\
\hline Standard Value & \\
\hline Standard value unit & \\
\hline \multicolumn{2}{|c|}{ Figure 14 Dissipation factor as SAP parameter } \\
\hline
\end{tabular}

\begin{tabular}{|l|l|}
\hline Formula key $\quad$ F1 \\
\hline Formula \\
\hline K4 4 K6 $) / \mathrm{K} 6$ \\
\hline
\end{tabular}

Figure 15 Formula key for dissipation factor in SAP

Formula key F3, as a more complex example, is shown in Fig. 16. It is visible that space provided in SAP for formula definition could sometimes be a problem for complex technical equations.

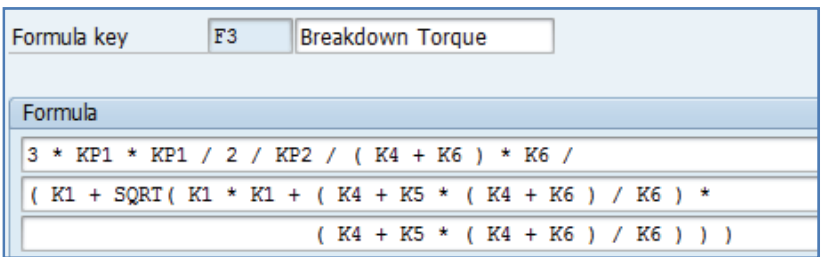

Figure 16 Formula key for breakdown torque

For electromagnetic torque $T_{\mathrm{em}}$, described by Eq. (4), parameter P04 and formula key F4 are created:

$$
T_{\mathrm{em}}=\frac{2 T_{\max }}{\frac{s}{s_{\max }}+\frac{s_{\max }}{s}} .
$$

For rotor current $I_{2}^{\prime}$, described by formula (5), parameter P05 and formula key F5 are created:

$$
I_{2}^{\prime}=\frac{V_{1}}{\sqrt{\left(R_{1}+\sigma_{1} \frac{R_{2}^{\prime}}{s}\right)+\left(X_{1 \sigma}+\sigma_{1} \cdot X_{2 \sigma}^{\prime}\right)^{2}}} .
$$

\subsection{SAP Master Data}

In order to include previously created formula keys and parameters in our analysis, three kinds of master data should be created in SAP: Materials, Work centres and Production routings. They will be simulation carriers.

\begin{tabular}{|l|l|}
\hline Material SLIP & FER - IM slip \\
\hline General Data & \\
\hline Base Unit of Measure $\quad$ Percentage Material Group \\
\hline \multicolumn{2}{|l|}{ Figure 17 Slip as material in SAP } \\
\hline
\end{tabular}

The first step is creation of material master data that will later be used for definition of slip value in percentage (Fig. 17). What follows is the inclusion of previously created parameters and formula keys in production work centres.

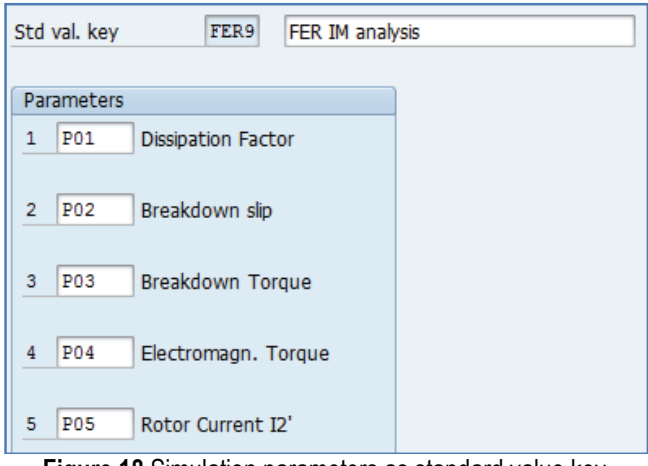

Figure 18 Simulation parameters as standard value key

For the beginning, the standard value key FER9 is specified, as group of parameters which will be monitored during simulation (Fig. 18). Then the formula keys F1 to F5 should be added to work centre and connect to corresponding parameter P01 to P05 (Fig. 19).

\begin{tabular}{||ll|l|}
\hline \multicolumn{1}{|c|}{ Activities Overview } & & \\
\hline Alt. activity descr. & Formula key & Formula description \\
\hline Dissipation Factor & - F1 & Dissipation Factor \\
\hline Breakdown slip & F2 & Breakdown slip \\
\hline Breakdown Torque & - F3 & Breakdown Torque \\
\hline Electromagn. Torque & $\mathbf{V}$ F4 & Electromagn. Torque \\
\hline Rotor Current I2' & $\mathbf{F 5}$ & Rotor Current \\
\hline
\end{tabular}

Figure 19 Formulas in Work centre

For existing material master data (slip), a Production routing should be created, as a basic set of master data needed for successful simulation (Work centre FER201 used in this example is one of parameters inside routing, Fig. 20).

After creating all parameters and formulas in SAP, the basic structure is ready for simulation and creation of steady-state characteristics.

\begin{tabular}{|l|ll|}
\hline Operation & & \\
\hline Operation/Activity & 0010 & Suboperation \\
\hline Work center / P1nt & FER201 $/ 1000$ & FER Induction Machine \\
\cline { 2 - 2 } Control key & PP01 & In-house production \\
\hline Standard text key & & Simulation \\
\hline
\end{tabular}

Figure 20 Work centre as part of Production routing

\section{SIMULATION}

There are two more things to be done in SAP, in order to have a successful simulation with resulting steady-state characteristics: 
- $\quad$ creation of Production order

- several confirmations of Production order with collecting data for each confirmation.

For production order creation (Fig. 21) previously created Production routing is used as a template. Production order should be created for maximum slip value, $100 \%$.

\begin{tabular}{|c|c|c|c|c|c|c|}
\hline Order & 60003847 & $\not 2$ & & & & \\
\hline Material & \multicolumn{2}{|l|}{ SLIP } & \multicolumn{4}{|c|}{ FER - IM slip } \\
\hline Status & \multicolumn{4}{|c|}{ REL PRC MANC NMAT SETC } & 田 & \\
\hline User Status & \multicolumn{4}{|c|}{ RLAL } & & \\
\hline General & Assignment & Goods & Receipt & Control & Dates/Qties & Master Data \\
\hline \multicolumn{7}{|l|}{ Quantities } \\
\hline Total Qty & \multicolumn{2}{|l|}{100,000} & 8 & Scrap Portion & & \\
\hline Delivered & \multicolumn{2}{|l|}{0,000} & & Short/Exc. Rcpt & 0,000 & \\
\hline
\end{tabular}

Figure 21 Production order for simulation

Simulation will be done through business activity named Production order confirmation. Orders will be confirmed for different slip values, from $1 \%$ to $100 \%$.

Formulas F1 to F3 are slip independent, while formulas F4 and F5 are slip dependent. The last two formulas should be read for each simulation (Production order confirmation) step and given values for electromagnetic torque and rotor current should be collected. At the end, for these two parameters, simulation curves for steady-state model of induction machine can be created.

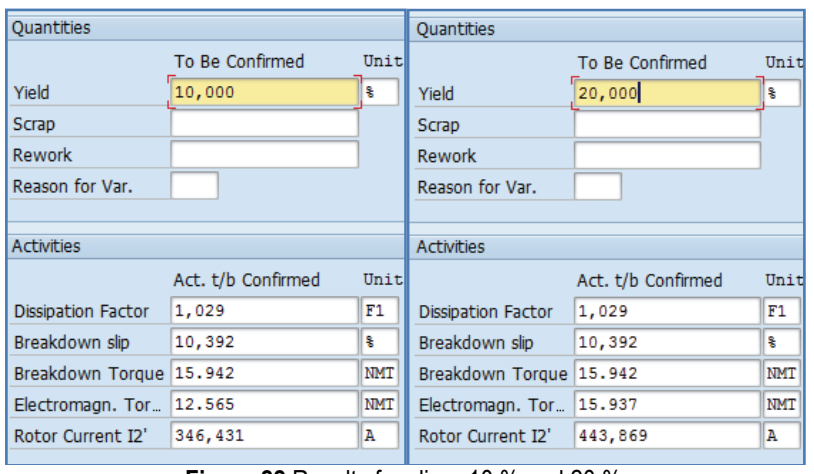

Figure 22 Results for slip $=10 \%$ and $20 \%$

Fig. 22 shows the SAP screens for production order confirmation for two simulation steps and slip's values of $10 \%$ and $20 \%$.

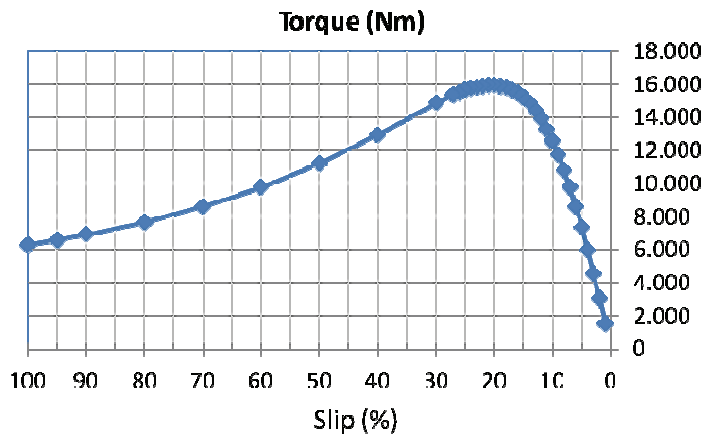

Figure 23 Torque-slip curve
Fig. 23 shows the final curve (created in excel) for steady state torque-slip characteristic.

All dots are calculated by SAP, but curve alone is created in excel. In the same way the curve for currentslip characteristic can be done.

In order to create such simulation curve in SAP, an additional ABAP (programming language used by SAP) program has to be created, because creation of such specific diagrams is not provided by standard SAP ERP software.

\section{CONCLUSION}

The possibility of using business software for analysis of electric machines is still an unknown area whose research requires specific combination of competent knowledge and experience in at least three scientific fields: electrical engineering, business processes and ERP systems.

This paper presents a case with induction machine analysis using SAP ERP as business software. Here, it is described how to calculate the values of equivalent circuit parameters, how to transform technical equations to SAP formula keys and how to get steady-state torque-slip characteristic. Three SAP modules are used, with only standard functionalities, and without any additional programming.

The next and third possible step in using ERP software for electrical machinery analysis is related to the area of business decision making. First research done in this field showed the possibility of helping highpositioned managers (as "natural" users of ERP software) in finding quick answers to critical questions regarding feasibility, costs and scheduling of possible projects. If such option is accepted, then this paper can be viewed as a solid base for the very first step in that direction.

\section{REFERENCES}

[1] Krause, P. C., Wasynczuk, O., \& Sudhoff, S. D. (2013). Analysis of Electric Machinery and Drive Systems. IEEE Press. https://doi.org/10.1002/9781118524336

[2] Dolenc, A. (1970). Induction Machines. University of Zagreb.

[3] Akhtar, J. (2013). Production Planning and Control with SAP ERP. Galileo Press.

[4] Jordan, J. (2012). Product Cost Controlling with SAP. Galileo Press.

[5] Blumohr, U., Munch, M., \& Ukalovic, M. (2012). Variant Configuration with SAP. Galileo Press.

[6] Nad, J. (1998). Energy saving and reliability increasing by application of regulated electrical drives. Master thesis, University of Zagreb.

Contact information:

Josip NAĐ, MSc, MBA

Konex d.0.0.

Eugena Kumičića 49, 42000 Varaždin, Croatia

josip.nad@konex.hr

Mario VRAŽıĆ, PhD, Professor

Faculty of Electrical Engineering and Computing

Unska 3, 10000 Zagreb, Croatia

mario.vrazic@fer.hr 